\title{
RECONCILING ENERGY COST \\ WITH A COMFORTABLE INDOOR CLIMATE: A PRACTICE-ORIENTED DESIGN PERSPECTIVE
}

\author{
SVENJA JAFFARI \\ UNIVERSITY OF SOUTHERN DENMARK \\ JACOB BUUR \\ UNIVERSITY OF SOUTHERN DENMARK
}

This paper argues that comfort is a social practice, rather than a stable condition caused by controllable indoor climate parameters. It is based on ethnographic field research in different types of Danish dwelling, which brought to light six comfort practices formulated to inspire the design and engineering of indoor climates and environments. The concept of comfort practices is of major importance when the goal is to change private energy consumption patterns towards a sustainable future. This investigation extends the existing body of research about the relation between comfortable indoor climate conditions and human health, productivity and energy costs with a practice-oriented approach to understanding what indoor climate and comfort means to people in their everyday lives.

\section{Introduction}

In the design of the indoor climate of buildings, a limited set of physical comfort parameters (e.g. light, heat, air, and noise) has conventionally been in focus to establish optimal conditions between people and their immediate physical surrounding (Fanger, 1970). Almost a century ago, the concept of the 'comfort zone' was technically defined within very narrow ranges (for a complete definition, cf. Yaglou, 1949 in Auliciems, 1981). This definition was based on an unrealistic ideal of unlimited natural resources and a scientific dream of mastering nature (Shove, 2003), through the creation of 'an indoor environment of constancy' (Brager and DeDear, 2003) and complete control of indoor climate through measurements (Hubbard, 1928). The idea of engineered comfort led to the development of energy-intensive, 
standardized indoor climate technologies such as electrical lighting, heating, air-conditioning, mechanical ventilation, and insulation that were often fixed and controlled by automated systems. Both Cooper (1982) and Cole and Steiger (1999) claim that this was simply due to the assumption that people acted in an error-prone, ambiguous, random and illogical manner, which is why they would 'mess' with prevailing indoor climate technologies. Since then, the scientific investigation and standardization of indoor climate and comfort has presupposed that people accept an artificial, homogeneous, and energy-intensive climate zone (described as an 'artificial bubble' in Shove, 2003) and thus, globally and locally, converging conventions and expectations, which are independent of outdoor conditions and situational variation (Healy, 2008; Strengers, 2008).

Recent work in sociology has explored conventions and expectations of standardized indoor climate control and comfort, placing them in relation to future paths of environmentally sustainable development (Shove, 2003). According to sociologists' cyclic model of production, consumption and use (for a complete definition, cf. Ingram, et al., 2007, p. 3), some of these studies articulate that the interaction between people's practices and new product designs becomes central to the shaping of any (un-)sustainable futures.

Empirical investigations of everyday practices (e.g. Hargreaves, 2011; Shove et al., 2004b) thus become relevant to designers, particularly in the area of Design for Sustainability. In her manifesto, Shove (2006, p.1) suggests some tenets of such a practice-oriented perspective on product design:

[Practice-oriented Product Design] holds that practices are the basic unit of society [i.e.] the routinized ways of doing, understanding, knowing, and desiring which comprise human experience and social structure at all scales. It is in the performance of practices that users and products come together, in complexes of skills, meanings, materialities and temporalities. It is in understanding the dynamics of practice and in identifying points for intervention that the power of [this approach] resides.

This practice-oriented perspective on product design recognizes that practices unfold over time and space, and hence call for both quantitative and qualitative research methods (e.g. data sets, statistics, market research, ethnographic accounts of situated practice) (Shove, 2006).

Recent research in the design discipline, in the areas of Computer-Supported Cooperative Work (Suchman, 1987; Szymanski and Whalen, 2011), Participatory Design (Kensing, 2003; Schuler and Namioka, 1993), and Intuitive Design (Fulton Suri, 2005; Wakkary and 
Maestri, 2007), resonates with principles and methods of inquiry suggested in Shove's Practice-oriented Product Design (2006). Designers have begun to consider social practices and meaning-making processes instead of users' individual cognition as the central unit of investigation. Some have investigated people's common, but complex and unexpected ways of integrating and adapting (non-)technological materials in their everyday lives at home and at work - i.e. people's situated, practical actions with technology that includes activities of (re-)designing (non-)technological products (i.e., Wakkary and Maestri, 2007). Often, these studies include a wide range of applied qualitative research methods (e.g. 'participant observation' in Hammersley and Atkinson, 1983; Spradley, 1980) that aim at providing 'thick descriptions' of situated use practices (Geertz, 1973). Such qualitative data ought to 'enable designers to question the taken-for-granted assumptions embedded in the conventional problem-solution design framework' (Anderson, 1994, p.158). That is why findings are often staged in material forms (e.g. scenarios, prototypes, critical designs), to provoke the design team and challenge conceptualization, affordability and opportunities of (both existing and future) technologies and interaction possibilities (Gaver and Martin, 2000; Mazé and Redström, 2008).

In light of these studies, design research has taken an interest in a practice-oriented perspective on design, as well as in the investigation of routinized ways of doing. Common with Shove's (2006) sociologically grounded Practice-oriented Product Design, it recognizes the power of designers who, by introducing new technologies or 'things' to the context, influence not only people's local perspectives but also global directions of conventions and expectations. Also, both perspectives problematize cognitivist approaches, acknowledging instead that people's motivations and decisions are situated and grounded in a particular context.

However, in qualitative (design) investigations of situated practices, the topic of indoor climate and comfort is still under-represented. It has been suggested that the reason for this might lie in the immeasurability and complexity of the concept of indoor climate-related comfort as such (Cole et al., 2008). Nevertheless, it seems to be an important topic when considering the considerable quantitative efforts in engineering to model energy consumption of standardized buildings and, most interestingly, the actual management of indoor climate products and systems across the world, both prior to (e.g. in Monahan and Powell [2011]) and after occupation (e.g. in Bernardi and Kowaltowski, 2006; Vinther Andersen et al., 2009). Even more so, when reading the same conclusion across these studies - namely, that individual behavior and attitudes towards indoor 
climate and comfort have a potentially large effect on a building's overall energy consumption, and can help to shape a low-carbon society. We suggest that the focus on 'comfort practices' presents an exciting approach towards a purposeful investigation of comfort as it is understood and experienced by building inhabitants.

The approach has similarities to recent research endeavors that have come to question the very idea of comfort in our built environment and the scientific arguments it is based on. For instance, some architects take the position that indoor comfort needs to be seen in a 'much broader sense than the conventional view, i.e., the provision and maintenance of a fixed set of thermal, luminous and acoustic conditions' (Cole et al., 2008).

The quantitative results of engineering research and the architectural viewpoint challenge policymakers' and indoor climate technologists' recent approaches towards the realization of a lower-carbon society that counters a scarcity of natural resources and global warming. In general, these approaches depend on raising awareness of environmental issues and reducing citizens' own resource consumption, often with financial incentives (e.g. rebates, grants, tax reductions) and deployment of smart technological devices. Policymakers and indoor climate technologists predominantly follow the dogma of information, monitoring devices, and automated control of a fixed set of indoor climate parameters.

This dogma has been questioned in design research on energy consumption in households. Pierce et al. (2010) claim that monitoring and control devices (e.g. feedback and awareness systems) might only guide people towards a temporal behavioral change of single and isolated actions in favor of environmental sustainability (e.g. turning off the lights) instead of a long-term change in entire practices.

With our study, we propose that a practice-oriented approach to indoor climate-related comfort and technology can help engineers and architects to understand intangible aspects in people's lives when consuming energy (e.g. behavior, attitudes, etc.). In particular, we like to contribute to the discussion about how to reconcile people's comfort experience with the common demand for a lower-carbon society (Cole et al., 2008), and make an argument for the importance of situational variation and ways of controlling indoor climate comfort. We hope to stimulate with this study a reconceptualization of what present and future sustainable buildings, indoor environments and specifically indoor climate technologies, which consider these aspects, look like. To sum up, with this study we stimulate a broader discussion of fixed engineering conceptualizations of indoor climate and comfort (e.g. the 'comfort zone'), of policymakers' strategies (e.g. financial incentives), and of efforts in design towards smarter monitoring and control 
technologies (e.g. feedback and awareness systems).

We will first give a short introduction to the ethnographic field study of everyday ways of managing indoor climate and comfort. Second, we elaborate in detail on six comfort practices extracted from field recordings, and add questions to guide design research and design practice. We close with a general discussion and conclusion.

\section{Field Research on Indoor Comfort}

Within a larger research project on user-driven innovation in indoor climate industry, we studied five families in Denmark in collaboration with industrialists and research colleagues. The families were chosen with a suitable spread of building types. Our assumption was that those with young children would have a high awareness of indoor climate and comfort. Each family study included combined ethnographic fieldwork in their private home, in one parent's office, and in the children's kindergarten, as we expected in this way to cover both private and professional practices, and also the environment in which such practices are learned. We spent two to three days with two researchers in each context (private home, office and kindergarten) for each family, and all studies were completed in the 'heating period' October to June.

As for design ethnographic techniques, we conducted participant observation and interviews (both open conversations and semi-structured interviews), documenting these in fieldnotes, audio and video recordings. We also registered the main engineering parameters with both stationary and portable measuring instruments. Design research tools included on-site probes and diaries. To find out how existing comfort practices unfold in these everyday life settings, our questions concerned the way in which people care about indoor climate control and how they 'mess with an automated system'(Cooper, 1982). We included questions about their experiences of seasonal variation and particular circumstances under which they are tolerant of a greater range of indoor climate conditions. We also inquired into people's conceptualization of a 'good' (or 'bad') indoor climate, and into motivations that make them act in certain ways. Overall, we empirically investigated how people actually deal with a given indoor environment and how they integrate corresponding technologies in their everyday lives. 


\section{A Set of Comfort Practices}

\section{Making Comfort}

In contrast to an understanding of comfort as a commodity delivered by indoor climate technology, we have found empirical grounding for an alternative notion that people actually achieve comfort with the help of their environment. Across the three contexts (private homes, offices, kindergartens), comfort appeared to be what people 'make' in terms of how they organize, how they build habits and how they control their environments.

We have seen specific ways of 'making comfort' in the ways in which families, office employees and kindergarten teachers organize to balance comfort with energy savings. When parents turn up the floor heating and the towel heating rack for their bathing children, knowing that it is more expensive, and when employees determinedly override the automatic controls ('we usually pull the contacts') to open doors and windows in the office, they consciously 'make' their individual comfort. Particularly in kindergartens, we have seen that this 'making' is learned early on as 'good indoor habits'. One headmaster told us that the teachers greatly appreciate order and structure to create a stable and recognizable everyday routine for both adults and children. That is why, for instance, the headmaster introduced a specific table-setting routine (Figure 1):

When we set the table for lunch, the children sit on the stairs to calm down and let this week's 'table setters' set the table and do the job that they take so much pride in doing. Everyone has their own place, so that there are no arguments about who should sit with whom and where one should sit. So one relaxes and has a nice time with the children one is sitting next to.

This indicates to us that teachers 'make comfort' and guide their own comfort experience by taking control. Likewise, office staff appreciated having influence over their environment; for instance, by being able to 'decide on [their] own how much light and [which] decorative elements [they] want', as one facility manager put it. Even in cases where indoor climate technologies (heating, ventilation, automatic shades, etc.) are operated by a facility technician, employees still try to stay in control by individually putting on 'an extra sweater' or arranging 'big posters in the windows'. 
Figure 1 In Kindergartens - 'I Admit That I Like Structure'

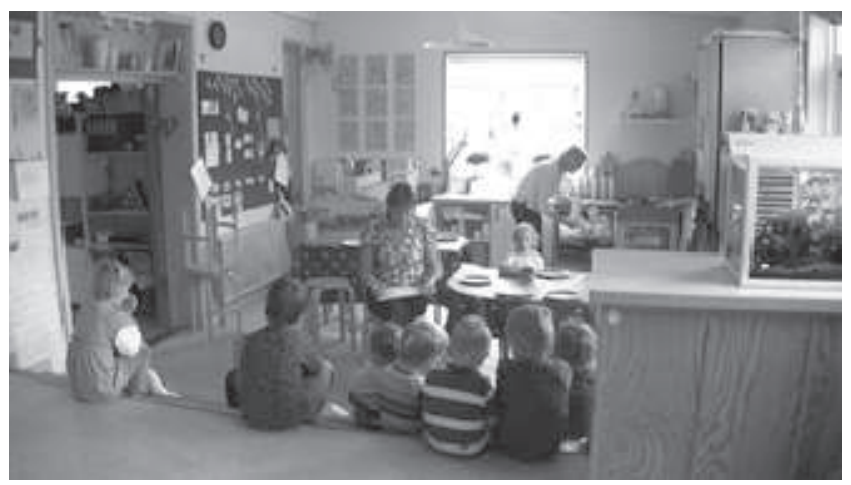

We have found that the ways in which people choose to control conventional indoor climate parameters largely depend on situation and time. For instance, a family told us that they often air out a particular bedroom for an entire day because 'there is a strange smell all the time' and 'there is no need to keep the room warm [because] it is only a bedroom'. In contrast, teachers avoided opening windows or backdoors in the kindergarten in the early lunchtime hours, even if the indoor climate was unsettling ('there is thick, clearly more dense air'). This was due to concerns about children's immediate health, safety and management ('the children would be exposed to draught or would want to go outside [...] and we would have to go after them'). This tendency to postpone ventilation also prevailed when the kindergarten had its roundtable meetings involving all the children and teachers. For children to confidently tell a story or voice a concern to the others, it is crucial to establish a feeling of security and encapsulation, minimizing the risk of disturbance by external noise. This is an example for how teachers (and children) 'make' comfort in a specific situation with the help of material surroundings, institutional roles and processes, images and responsibilities at both individual and collective levels.

When we look at indoor climate control as ways of 'making comfort', crucial questions for design arise: How might designers, who are developing new products for environmental sustainability, intervene in people's everyday comfort practices to help balance 'making comfort' with energy costs? How can designers prompt energy-conscious indoor climate habits while also allowing for personal control and individual guidance of comfort experiences? When considering these questions in the design of future technologies, designers can raise greater awareness of natural 
resource shortages and climate change while at the same time encouraging people to be more self-reliant and adaptable (e.g. to alternative strategies of heating and cooling).

\section{'Doing Social Relations'}

A practice-oriented approach challenges not only conventional engineering methods (e.g. heat-balance calculations, climate chamber testing) and designs, but also the general idea of modeling real-life situations out of context. From our observations, we can see that indoor comfort is undoubtedly formed in people's social world, in their social relations, rather than in a sealed chamber with optimized physical comfort parameters. Families, office staff, and kindergarten teachers achieve indoor comfort through what we have called ways of 'doing social relations' in terms of being heard and seen, and in terms of finding consensus within a framework of conflicting opinions and differing understandings.

We observed families in two private homes who had developed recognizable routines 'doing social relations' around their individual heating preferences, based on each family member's social roles and relationships. For instance, one of the parents preferred a warmer room and set the thermostat higher. However, the setting was soon reverted by the other parent ('my husband used to put [the thermostat] on two, or even higher; but then, when he's not looking, I just put it back to zero').

In order to cultivate these important routines and social relationships, we found that not only families but also office staff and kindergarten teachers appreciate being given a voice - that is, they like to be heard and seen in an environment, even if this requires them to negotiate with conflicting opinions and understandings. Where some relate easily to certain indoor climate technologies, others have difficulty and prefer to avoid intervention. For instance, report forms sent by the district heating company to homes, or by the city hall to kindergartens, were not completed due to difficulties in finding and correctly interpreting the numbers on a specific installation. In cases where families and kindergarten teachers felt obliged to 'fill in the form [that had been sent], [they still had] no idea what it meant' (Figure 2).

When many people try to integrate diverse individual and collective priorities and interpretations, it can be challenging to find solutions that they can genuinely agree upon. In kindergartens, for instance, teachers organized [themselves] out of any kind of conflict that makes someone feel ill at ease'. Some of these problematic issues - e.g. a teacher feeling particularly cold in a room assigned to her group of children - could have 
been caused by specific routines, such as (re-)arranging the environment so that it meets pedagogical aims yet negatively affects local indoor climate conditions; for instance, in cases where teachers were leaving an entrance door ajar to accommodate frequent parent goodbyes (Figure 3), indoor temperature dropped and airflow increased, resulting in 'a playroom [being] not warm enough'.

Figure 2 At Homes - 'The Numbers Mean Absolutely Nothing To Me'

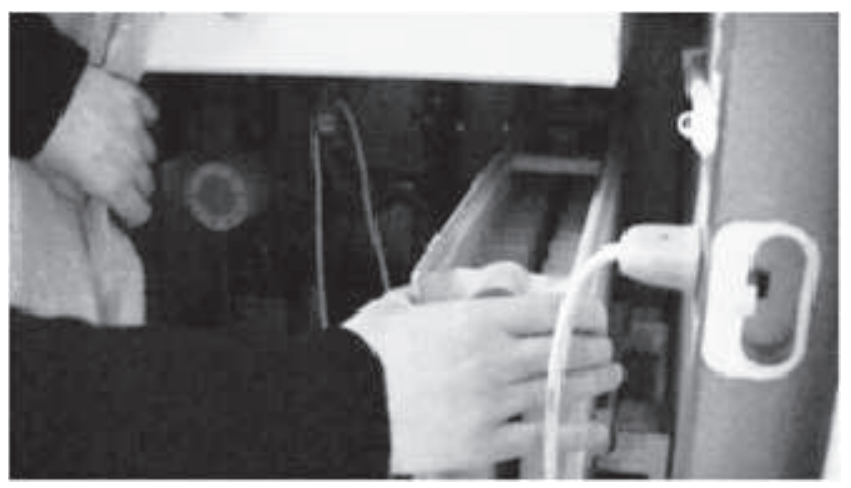

Figure 3 In Kindergartens - 'They Like To Wave Goodbye'

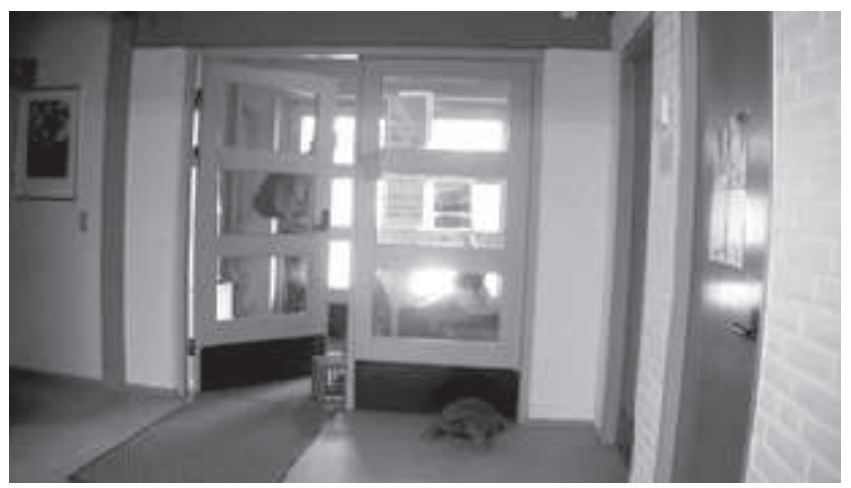

How and whether these situations get resolved depend on a variety of influences, including expert advice, personal experience and perceptions, hearsay, individual preferences (e.g. in Jaffari and Matthews, 2009; Kempton et al., 1992), which again need to be agreed upon. 
From the above, we propose that comfort is practised in people's everyday lives as 'doing social relations'. This introduces challenging questions for design practice: How might designers democratize indoor climate by giving people the tools with which to participate, to realize and negotiate different understandings, and to find agreement among each other? Again, design plays a significant role in reconciling public demand for lower energy consumption with experience of comfort. Designers can create interventionist tools that allow for people's everyday comfort practices to continuously evolve towards a sustainable future indoor climate and optimal comfort.

\section{Becoming Healthy}

Recent engineering research on indoor climate and comfort has focused on building materials and climate control in relation to human health. In cases of negative health effects, materials and indoor climate parameters are usually optimized to restore a healthy indoor environment: indoor air quality (Bakó-Biró and Olesen, 2005), daylight (Baker and Steemers, 2000), noise (Kowaltowski et al., 2002), and thermal conditions, especially with regard to the vulnerable and elderly (Diaz et al., 2002). Researchers from other disciplines (e.g. psychology and nursing) have tied human health to 'situational factors' such as colors, furniture, views to the outside, and past experiences (Heerwagen and Heerwagen, 1984; Kolcaba, 2003). From our field observations, we can see that being - and even more so, becominghealthy is an important way of doing comfort in everyday life.

To 'become healthy', families, office staff, and kindergarten teachers use their sight, hearing, touch, smell, and taste in making sense of their environment. Especially when they feel out of balance or are obviously unwell, they follow common-sense measures, such as turning up the lights and changing position (e.g. oneself, others and things), shielding and attuning, airing out and refreshing. We saw families occasionally change the 'too much and too bright' lighting at home to put 'focus on the place where [they are]'; or, in offices, employees would call the janitor to close the ventilation system, or 'draught channels' (Figure 4), because they felt a pain in their shoulder and neck.

In kindergartens, children's toys were considered 'a big source for spreading diseases', so they were cleaned thoroughly twice a year. By immediately responding to ongoing developments in their surroundings, teachers improve their own and the children's health and at the same time establish a purposeful relation with the environment. 
Figure 4 In Offices - 'I Start to Get Head- and Neck- aches'

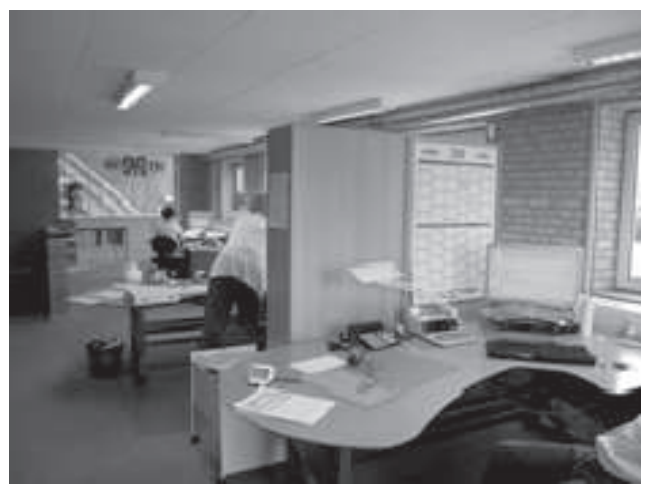

Many of the recent indoor climate technologies tend to rely on calculations, models and scenarios of passive recipients in an optimal environment. Not surprisingly, such technologies can have difficulty accommodating real people, who behave ambiguously, manipulate or 'mess with' the automated system (Cooper, 1982). During one of our field visits, a family left both entrance doors open on a warm summer day because the mother was hanging laundry and the children were playing outside; but in this case, their 24-hour ventilation system could not work according to plan and prevent high levels of pollen inside the house. Though appearing ambiguous, messy and counteractive at first sight, such behavior actually serves the purpose of learning about technologies as well as judging one's bodily condition in relation to the immediate environment.

Designers who understand comfort as ways of 'becoming healthy' can contribute to a conceptual shift in sustainable (building) design and engineering - from people as passive occupants of a climate zone (e.g. with particle-free air and neutral thermal conditions), towards people as active inhabitants who tune their senses, become aware of, and actively create a healthy environment. What we suggest is that designers might develop sustainable indoor climate technology that takes account of people's existing and potential sensitivities towards their environment. In contrast to the development of automated control systems, such technology designs raise the question of how to create opportunities for people to learn to act on ongoing developments and on their subjective feelings of well-being. 


\section{Bringing Feeling, Observing, and Understanding in Tune}

When considering current indoor climate technologies, there appears to be a gap (as well as an opportunity) with regard to aligning individual actions and situated goals with the invisible and ungraspable nature of indoor climate and comfort. In our ethnographic investigation into everyday life, we have noticed that these technologies often do not integrate people's ways of intimately feeling their own bodily responses, observing changes in the environment, and becoming consciously aware of causal relationships. In order to 'bring feeling, observing, and understanding in tune', families, office staff, and kindergarten teachers seek expert advice to understand how their own actions influence the performance of indoor climate systems, experimenting with the comfort experience to train their own perceptions.

For instance, when families faced deficient indoor climate technologies at home, they often sought the advice of someone they knew, such as a neighbor, family member, or local plumber; or checked the Internet, television or magazines. In one case, for instance, a home-based central heating system released a great surplus of heat into the open air. The family contacted a local expert, who reassured them that such surplus heat is a 'common feature of the type of house' they had bought. Consequently, the family found ways of adapting to this otherwise inadequate comfort zone, such as by using the extra heat to dry laundry (Figure 5).

Figure 5 At Home - 'We Asked the Plumber [... And] Use the Extra Heat for Drying Our Clothes'

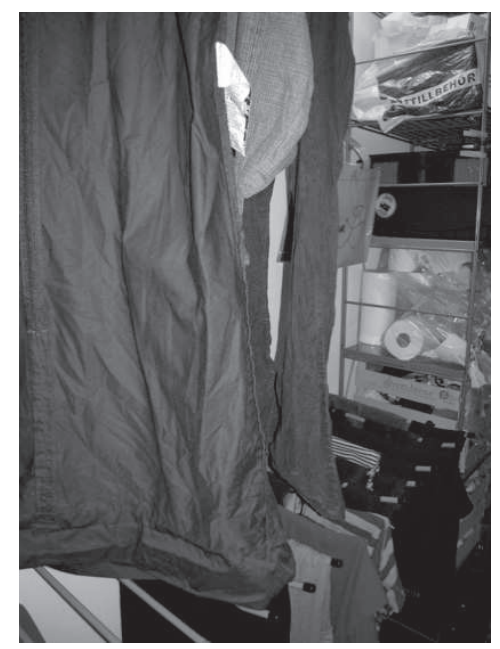


In kindergartens, we encountered teachers who tried to maintain awareness of their physical state, observing any changes and actively seeking advice, thus indicating that they were genuinely interested but had difficulties in relating their actions to technology functions ('How does [a ventilation system] actually work [in] the way it should?'). To solve unusual or unsatisfactory indoor climate experiences, they actually seemed to enjoy experimenting with technologies, exploring relations and varying their own levels of comfort. The headmaster of one kindergarten explains this practice:

Even though we have been working here for twenty years, we haven't felt stuck. We haven't had time to find a different job [smiling]. What could be different here is not because of, but despite of. We experiment all the time with our relations, and all the time new regulations and rules get introduced. For instance, at the moment we're trying out a new meeting structure for staff meetings. We'd like to get away from staff meetings in the evening, or change the meeting in the evening to information meetings only. [...] Another result of our experimental approach is the fold-up tables. We've had them especially made for us, to make the rooms more flexible.

Self-established rules and official regulations may maintain constraints and important prerequisites that enable people to experiment with their indoor climate experience. When families do not consider, for instance, uninstalling an old-fashioned, energy-intensive light sensor, or moving the fridge out of a heated room at home, they probably feel less personally obligated, and public regulations will not reach so far as to make them do so. When asked about it, some gave excuses ('I had no time to change these') or occasionally confessed to a guilty conscience. In contrast, when office staff successfully persuaded facilities management to remove sunshield foil from the windows, they were negotiating both social conventions (to collectively stand behind a proposal) and official regulations (like building standards).

Ways of 'bringing feeling, observing, and understanding in tune' encompass not only people's experiments, but also training of the environmental perception that was once vital for survival. When confronted with mold in a child's bedroom, for instance, one family needed to establish a strategy to remedy this unhealthy environmental condition in accordance with their particular circumstances. But because the father had wrongly reassembled a radiator thermostat, they could not passively rely on the technology, i.e. the radiator's set points to keep the room warm. They had to train their own perception to determine the correct thermostat setting, which now differed from the officially recommended set point. In kindergartens, teachers guided children towards developing their own environmental 
perception and sensitivities ('[the children] have to begin to learn to feel themselves'), such as in deciding what to wear when going outside (Figure $6)$.

Figure 6 In Kindergartens - 'They Need to Start to Teach Themselves What to Wear'

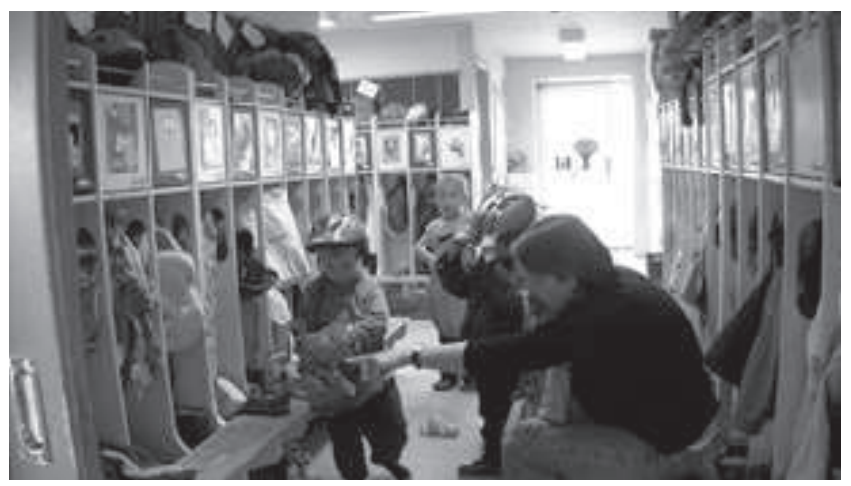

With the notion of 'bringing feeling, observing, and understanding in tune', we problematize the preference for automated and centrally controlled indoor environments that are so common in engineering. Design practitioners can support this comfort practice by developing design interventions and technologies that encourage people to take responsibility for their indoor climate decisions - especially those that enable people to experiment, explore, and link their own actions to product performance. Such designs might help people to achieve a nuanced environmental perception and sensitivity that can align individual actions and feelings with the invisible, experience-based nature of indoor climate and comfort.

\section{Connecting to the Outdoors}

The mantra in sustainable building design is to create an effective and energy-saving 'building envelope' consisting of walls, roofs, doors, windows, and insulation (Koçlar et al., 2002). To do this, one relies on current comfort standards as defined by ASHRAE (American Society of Heating, Refrigerating and Air-conditioning Engineers), ISO (International Organization for Standardization), or CEN (European Committee for Standardization). Both the concept and standardized realizations of such an 'envelope' are based on the idea of sealing people off from outdoor influences (e.g. air, noise, heat); they disregard everyday dynamics and 
in-betweens of indoor climate and comfort (Shove et al., 2008). From our observations, we can see that everyday comfort transcends the building envelope by people 'connecting to the outdoors' - through situations in which families, office staff, and kindergarten teachers either actively manage 'gray zones' of indoor/outdoor climate or negotiate different perceptions of inside/outside.

In kindergartens, teachers and children frequently move between the inside and outside ("we try to go outside [with the children] at least once a day'). For instance, they put on or take off clothes or (temporarily) utilize the building structure, windows, trees, and outside areas to adapt to different climate conditions and their own varying comfort experience ('[the children] come inside to get away from the sun, to calm down, to get some fruit and a lot of water before going outside again'). We observe that people use a broad repertoire of adaptive strategies (Humphreys, 1995) for different environmental conditions.

When families build glass verandas, or even when they buy wooden furniture for their private homes ('wood gives a good indoor climate'), they 'connect to the outdoors' through negotiating perceptions of inside/outside. Similarly, office staff can reconfigure or completely override built-in indoor climate technology in ongoing processes of dynamically experiencing and negotiating. This was especially the case with technologies that tried to break the direct link to the outside e.g., sunshield foil on the office window ('we put cardboard up in the windows [because foil is not enough]'; 'we removed parts of the [sunshield] foil because we always felt as if a giant thunderstorm was on its way') (Figure 7).

Figure 7 In Offices - 'Sometimes Someone Puts Cardboard Up on the Windowsill'

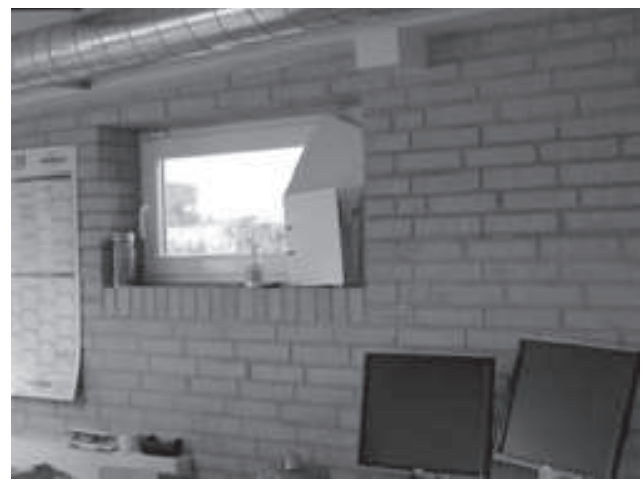


We suggest that designers could consider people as what might be called 'trespassers' of the building envelope, who refuse to be sealed off from outdoor stimuli and changing environmental conditions. People essentially need ways of 'connecting to the outdoors' to be comfortable, to negotiate between inside and outside experiences. We suggest that designers of sustainable buildings and indoor climate technology support people in this connection to the outdoors, by creating dynamic systems of environmental control that take account of the in-betweens of indoor/outdoor climate and allow partial relationships to be sustained between the inside and outside environment.

\section{Dealing with the Political Agenda}

Current policy efforts towards environmental sustainability support engineering approaches that make use of more intelligent monitoring and control technologies. Encouraged by engineers and economists, policymakers tend to focus on energy-efficient technology, perhaps underestimating the unpredictable influence of people's actions. Regulations and financial incentives (e.g. rebates, governmental subsidies) stimulate an economically rational market to adapt energy-efficient comfort technologies (Stern, 1992). Thus policymaking (perhaps unknowingly) restrains people from participating in actual decision-making. Our field observations suggest that the ways in which families, office staff, and kindergarten teachers 'deal with the (current) political agenda' surprisingly looks less like following existing rules and rather more like developing their own individual comfort agendas.

In Denmark, public administration regularly requires kindergartens to fill in forms about their (comfort-related) energy consumption, while expert evaluations are invited to uncover possible energy reductions. When confronted with such forms and evaluation reports ('we have to cut down our energy bill by $10 \%$ [each year]'), we noticed that teachers do not give these formal actions as high a priority as the municipality might assume ('I try to do it, but I don't know what [the municipality] will use [these forms] for'; 'It is unnecessary extra work'). Instead, they find their own ways of 'dealing with the political agenda' - such as by continuously discussing, arranging and altering institutional structures (regulations, standards, rules). By so doing, they generally end up following an individual agenda of indoor comfort. In one of the offices, for instance, the head of building management 'had just decided that [building management and employees] do not agree with [the standards] and therefore [had] to still implement individual desk lamps'. 
A broad range of such individual agendas of indoor climate conditions and energy consumption was especially apparent in private homes and kindergartens. During our field study, we met families who preferred the character and style of old buildings, regardless of current energy criteria. Some of the kindergartens had a similar approach: teachers rarely insisted on absolute control ('procedures describing when [one] exactly should do something [e.g. open the windows] can make people avoid taking responsibility'). On the other hand, we saw families who took pride in sustaining a low-energy building and were thus highly motivated to minimize energy consumption- sometimes even investing more than necessary in insulation ("we have more [than $250 \mathrm{~mm}$ of] insulation, especially in the floor, which only becomes a standard in a couple of years from now'), pursuing energy-saving tasks (e.g. replacing lights, installing sensors, and insulating pipes) and continuously monitoring overall energy usage (Figure 8).

Figure 8 At Home - 'I Got More Motivated to Save Energy'

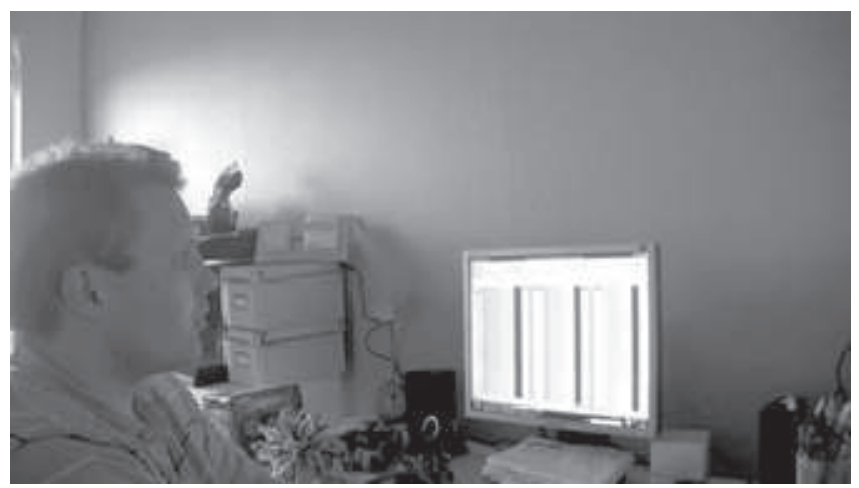

Such individual comfort agendas are socially negotiated and determined by motivating (or demotivating) factors beyond financial ones. Indoor climate technologies seldom consider the multitude of societal concerns such as budget, personal image, feelings of being safe and belonging to a community ('we want to contribute to environmental issues'). When the head of maintenance in an office was able to see that he could save heating costs, he lowered the overall thermostat setting; when families competed with others for a drastic cutback in home energy costs, they designed their own rigorous ways of energy metering (Figure 8). 
In contrast to such positive reactions towards sustainable comfort and energy savings, people sometimes faced situations that made it difficult to react in such a way; for instance, cleaners working alone in a kindergarten at night felt vulnerable, so decided not to air the rooms. In our observations, people are often part of several different social communities, each with its institutional processes, inherent social roles (e.g. employee, father, environmental activist) and situational circumstances. This meant that each of them dealt with the political agenda in their own way, their changes in comfort levels being influenced by multiple situational and variable social concerns.

We suggest that designers take a look at how comfort gets formed in people's ways of dealing with the political agenda. From this perspective, designers can challenge current perceptions in engineering (inscribed in building guidelines and standards) and policymaking by developing scenarios in which people actively participate in decision-making about future environmental policies. While policymakers focus on financial incentives for behavior change, designers can develop tools for people to practice sustainable comfort that address a much wider range of motivating factors and social concerns.

\section{Discussion}

When comfort within the indoor climate context is understood as ways of 'making comfort', 'doing social relations', 'becoming healthy', 'bringing feeling, observing, and understanding in tune', 'connecting to the outdoors', and 'dealing with the political agenda', then design for sustainable indoor environments and indoor climate technology face a different set of questions. What 'comfort' then really boils down to is how to facilitate people's understanding, negotiations and development of environmental sensitivities, how to form relationships between individuals and technology, and how to encourage participation and influence people's own actions. When these questions serve as directions for future design practices, they naturally make designers (and other industrial stakeholders) scrutinize taken-for-granted assumptions (Anderson, 1994, p.158) and simple solutions such as monitoring and control technologies based on a conceptualization of people passively occupying the built environment (Pierce et al., 2010). Rather than trying to change overt unsustainable behavior within the indoor climate context with the help of smarter technological devices, designers can focus on opportunities for rich interaction, exploration and creative adaptation in order to intervene in 
people's everyday (comfort) practices (see for example Gaver and Martin, 2000; Mazé and Redström, 2008).

Indoor climate engineering can also benefit from an appreciation of people's multiple ways of adapting to their environments. In line with other researchers who have investigated indoor climate management and the concept of comfort (e.g. Cole and Steiger, 1999; Kempton et al., 1992; Vinther Andersen et al., 2009), this study shows that people - in our case families, office staff, and kindergarten teachers- are very receptive to and appreciative of the opportunity to personally control their environment. Today's (low-energy) buildings and indoor climate technologies are designed to meet building guidelines and standards that take little account of the importance of personal control, people's adaptive strategies and everyday comfort practices. Although engineering tries to advance in the development of more accurate measures, controls and automation of the optimal indoor climate zone, it is less observant of people's everyday actions and decision-making. Based on our field observations, we argue that complete automation impairs people in feeling, observing, and understanding their own immediate surroundings and, on the larger scale, in connecting with nature and participating in any environmental discourse. What might be necessary is a change in the underlying philosophy of standardized environments (Humphreys, 1995, p. 7) to include human practices as complex but highly valuable resources in the engineering research and design process for environmental sustainability.

Also, our findings have significant implications for policymaking in the area of indoor climate and environmental sustainability. Due to policymakers' power over the shaping of future conventions, it is important to establish an appreciation of the people's diverse ways of 'doing' comfort in different environments in order to make informed decisions. At present, policymakers 'think technology first' and almost exclusively focus on how to change energy consumption behavior with the help of financial incentives for green technologies (Stern, 1992). By so doing, policymakers seem to shape a future, in which indoor environments converge worldwide into one 'homogenous, artificial' space (Shove, 2003). Our observations of everyday comfort practices indicate that there is actually considerable potential in enabling a more sustainable future.

Science and Technology Studies has particularly looked at what these futures could look like in the light of existing conventions of standardized indoor climate control (e.g. Shove, 2003). In Pett (2004), Shove and Chappells (2004a) summarize four future comfort scenarios developed with stakeholders from the policy and building sectors, together with ordinary inhabitants. In scenario I, 'The Comfort Zone Extends', people are 
comfortable in a much wider range of indoor temperatures. The building and fashion industries work according to "more "elastic" definitions of comfort', all of which help to reduce resource consumption. In scenario II, 'Indoor Climates Diversify', people value regional climate differences 'through, for example, reinventing cultural traditions' and thus agree with and adapt to rising temperatures. In scenario III, 'Standardized Efficiency', 'conventions of comfort and clothing stabilize' but are provided for in a far more efficient way (e.g. renewables, different controls, passive houses). Finally, in scenario IV, 'Escalating Demand', people's interpretations and rising expectations increase demand for cooling and heating, leading to a growth in resource consumption and emissions.

From our field observations, indoor comfort can indeed be formed towards the less energy-intensive scenarios I and II; people can extend their comfort zone to a much wider range of indoor temperatures by taking advantage of the building and fashion industries' more flexible designs. People can adapt to rising temperatures by appreciating regional climate differences and reinventing cultural traditions (e.g. reintroduce the siesta, wear a turban in hot desert regions). These 'future comforts' can be sustained through future generations and immediately lead to a substantial reduction in the consumption of natural resources. We suggest that policymakers might rethink future comfort scenario III, standardized efficiency (e.g. with the help of new green technologies), which they currently push. From our observations and literature research, we suggest that further non-adaptive standardizing may lead to an unsustainable escalation in demand for more heating and cooling, i.e. to future comfort scenario IV (cf. also Strengers, 2008).

We further see a potential danger in a standardized, efficient technology that completely controls and uniformly delivers comfort in terms of heating, cooling, and ventilating the indoor environment. When people live in such an indoor climate of complete control and constancy, they may no longer take responsibility for their environment. They would lose important ways of 'making comfort', 'doing social relationships', 'becoming healthy', 'bringing feeling, observing and understanding in tune', 'connecting to the outdoors' and 'dealing with the political agenda'. In other words, standardized comfort denies any situational, variable, normative, cultural, and idiosyncratic characteristics (Shove et al., 2008) and could become a negation of itself by ultimately raising environmental as well as societal costs (e.g. people's expectations, resource consumption, work-related illnesses, child education). To avoid this consequence, we suggest that policymakers encourage substantial research on actual (un)sustainable human practices and their adaptive capacities. 


\section{Conclusions}

Our contribution to existing efforts towards the practice-oriented design of sustainable buildings and indoor environments is formulated as six everyday comfort practices: 'making comfort', 'doing social relations', 'becoming healthy', 'bringing feeling, observing, and understanding in tune', 'connecting to the outdoors', and 'dealing with the political agenda'. We have shown the benefits of considering these everyday ways of 'doing' comfort in design, and we propose guiding questions to help create future sustainable indoor climate technologies that might be more readily accepted and serve to initiate a change in current comfort practices.

We problematized the manner in which indoor comfort is conceptualized and made operational by the engineering discipline namely, as a static, optimum level of a limited set of comfort parameters (e.g. humidity, temperature, light, noise, air quality) that is validated by calculation models and decontextualized climate chamber tests.

We challenged policymakers' approaches to minimizing resource consumption and maximizing efficiency through financial incentives, based on models from engineering and economics. In contrast, our study has shown that people may be able to develop other sustainable ways of 'doing comfort' in their everyday lives. For instance, we found that people's ways of 'making comfort', in terms of organizing, controlling, and building habits, clearly transcends the boundaries of a scientifically prescribed 'comfort zone' and is highly contextual. This finding interestingly relates to two scenarios for future comfort predicted elsewhere (Shove and Chappells, 2004a), in which 'the comfort zone extends' and 'indoor climates diversify'.

Finally, we proposed that not only design and engineering but also policymaking can be grounded in everyday comfort practices in a practice-oriented approach.

\section{References}

Anderson, R.J. (1994). 'Representations and requirements: the value of ethnography in system design.' Human-Computer Interaction 9(1), pp. 151-182.

Auliciems, A. (1981). 'Towards a psycho-physiological model of thermal perception.' International Journal of Biometeorology 25(2), pp.109-122.

Baker, N.,\& Steemers, K. (2000). Energy and Environment in Architecture: A Technical Design Guide. New York: E.\& F. N. Spon. 
Bakó-Biró, Z., \& Olesen, B. (2005). 'Effects of indoor air quality (IAQ) on health, comfort and productivity.' Overview Report, ICIEE, Technical University of Denmark, pp. 1-43.

Bernardi, N., \& Kowaltowski, D.C.C.K. (2006). 'Environmental comfort in school buildings: a case study of awareness and participation of users.' Environment and Behavior 38(2), pp. 155-172.

Brager, G.S.,\& De Dear, R.J. (2003). 'Historical and cultural influences on comfort expectations.' In R. Cole \& R. Lorch (Eds), Buildings, Culture and Environment (pp. 177-201). London: Blackwell.

Cole, R.J.,\& Steiger, M. (1999). 'Green buildings - grey occupants?' Web-Proceedings: American Institute of Architects/US Green Building Council-Mainstreaming Green Conference, pp. 1-14. Available at http://www.docstoc.com/docs/40422607/GREEN-BUILDINGS---GRE Y-OCCUPANTS---PDF (accessed 2014 April 14).

Cole, R.J., Robinson, J., Brown, Z., \& O’Shea, M. (2008). 'Re-contextualizing the notion of comfort.' Building Research \& Information 36(4), pp. 323-336.

Cooper, I. (1982). 'Comfort and energy conservation: a need for reconciliation?' Energy and Buildings 5, 83-87.

Diaz, J., Jordan, A., Garcia, R., Lopez, C., Alberdi, J.C., Hernandez, E. and Otero, A. (2002). 'Heat waves in Madrid 1986-1997: Effects on the health of the elderly.' International Archives of Occupational and Environmental Health 75, pp. 163-170.

Fanger, P.O. (1970). Thermal Comfort: Analysis and Application in Environmental Engineering. Copenhagen: Danish Technical Press.

Fulton Suri, J. (2005). Thoughtless Acts: Observations on Intuitive Design. San Francisco: Chronicle Books.

Gaver, W., \& Martin, H. (2000). 'Alternatives: exploring information appliances through conceptual design proposals.' In Proceedings of the SigCHI Conference on Human Factors in Computing Systems (pp. 209-216). New York: ACM..

Geertz, C. (1973). The Interpretation of Cultures. New York: Basic Books.

Hammersley, M.,and Atkinson, P. (1983).Ethnography: Principles in Practice. London: Routledge.

Hargreaves, T. (2011). 'Practicing behaviour change: Applying social practice theory to pro-environmental behaviour change.' Journal of Consumer Culture 11(1), 79-99.

Healy, S. (2008). 'Air-Conditioning and the 'Homogenization" of People and Built Environment.' Building Research \& Information 36(4), pp. 312-322. 
Heerwagen, J.H., \& Heerwagen, R. (1984). 'Energy and psychology: designing for a "state of mind". Journal of Architectural Education 37(3/4), pp. 34-37.

Hubbard, H.D. (1928). 'Measurement and human life.' The Science News-Letter 14(387), p. 152.

Humphreys, M.A. (1995). 'Thermal comfort temperatures and the habits of hobbits.' In F. Nicol \& M.A. Humphreys (Eds), Standards for Thermal Comfort: Indoor Air Temperature Standards for the 21st Century, London: Chapman \& Hall, pp. 3-13.

Ingram, J., Shove, E., \& Watson, M. (2007). 'Products and practices: selected concepts from science and technology studies and from social theories of consumption and practice.' Design Issues 23(2), pp. 3-16.

Jaffari, S.,\& Matthews, B. (2009). 'From occupying to inhabiting: a change in conceptualising comfort.' IOP Conference Series: Earth and Environmental Science, 8 012008, 1-14. Available at http://iopscience.iop.org/1755-1315/8/1/012008 (accessed 2014 April 14).

Kempton, W., Feuermann, D., \& McGarity, A.E. (1992). "I always turn it on super": User decisions about when and how to operate room air conditioners.' Energy and Buildings 18, pp. 177-191.

Kensing, F. (2003). Methods and Practices in Participatory Design, Copenhagen: IT University Press.

Koçlar Oral, G., Köknel Yener, A., \& Tamer Bayazit, N. (2002). 'Building envelope design with the objective to ensure thermal, visual and acoustic comfort conditions.' Building and Environment 39(3), pp. 281-287.

Kolcaba, K. (2003). Comfort Theory and Practice: A Vision for Holistic Health Care and Research. New York: Springer.

Kowaltowski, D.C.C.K., Labaki, L.C., Pina, S.A.M.G., Borges Filho, F.,\& Bernardi, N. (2002). 'Basic teaching instrument for awareness of environmental comfort.' 17th Conference of the International Association for People Environment Studies, La Coruña, Spain.

Mazé, R., \& Redström, J. (2008). 'Switch! Energy ecologies in everyday life.' International Journal of Design 2(3), pp. 55-70.

Monahan, J., \& Powell, J.C. (2011). 'An embodied carbon and energy analysis of modern methods of construction in housing: A case study using a lifecycle assessment framework.' Energy and Buildings 43(1), pp. $179-188$.

Pett, J. (2004). 'Cold comfort for Kyoto: the role of actors in reducing unconstrained demand for air conditioning in the domestic sector.' Proceedings of conference on Air Conditioning and the Low Carbon 
Cooling Challenge, Network for Comfort and Energy Use in Buildings( London).

Pierce, J., Schiano, D.J., \& Paulos, E. (2010). 'Home, habits, and energy: examining domestic interactions and energy consumption.' Proceedings of ACM conference on Human Factors in Computing Systems (pp. 1985-1994). New York: ACM.

Schuler, D., \& Namioka, A. (1993). Participatory Design: Principles and Practices. Hillsdale: Erlbaum.

Shove, E. (2003). Comfort, Cleanliness and Convenience: The Social Organization of Normality. Oxford: Berg.

-. (2006). 'A Manifesto for Practice Oriented Product Design'. Designing and Consuming Workshop, Durham, UK.

Shove, E., \& Chappells, H. (2004a). 'Future Comforts: Reconditioning Urban Environments.' Final report for the Economic and Social Research Council (ESRC), UK.

Shove, E., Pantzar, M. \& Hand, M. (2004b). 'Recruitment and reproduction: the careers and carriers of digital photography and floorball.' In M. Pantzar \& E. Shove (Eds), Manufacturing Leisure: Innovations in Happiness, Well-being and Fun. National Consumer Research Center: Helsinki. Available at http://www.lancaster.ac.uk/staff/shove/choreography/recruitmentandre production.pdf (accessed 2014 April 14).

Shove, E., Chappells, H., Lutzenhiser, L.,\& Hackett, B. (2008). 'Comfort in a lower carbon society.' Building Research \& Information 36(4), pp. 307-311.

Spradley, J.P. (1980). Participant Observation. New York: Holt, Rinehart and Winston.

Stern, P.C. (1992). 'What psychology knows about energy conservation.' American Psychologist 47(10), pp. 1224-1232.

Strengers, Y. (2008). 'Comfort expectations: the impact of demand-management strategies in Australia'. Building Research \& Information 36(4), pp. 381-391.

Suchman, L. (1987). Plans and Situated Actions. Cambridge: Cambridge University Press.

Szymanski, M.H., \&Whalen, J. (2011). Making Work Visible: Ethnographically Grounded Case Studies of Work Practice. Cambridge: Cambridge University Press.

Vinther Andersen, R., Toftum, J., Kaae Andersen, K., \& Olesen, B.W. (2009). 'Survey of occupant behaviour and control of indoor environment in Danish dwellings.' Energy and Buildings 41, pp. 11-16. 
Wakkary, R., \& Maestri, L. (2007). 'The resourcefulness of everyday design.' Proceedings of Creativity \& Cognition (pp. 163-172). New York: ACM.

\section{Acknowledgments}

The 'Indoor Climate and Quality of Life' user-driven innovation research project was financed by the Danish Business Authority (EBST). We are grateful to our field informants who let us take part in their everyday lives, as well as to the project team and our colleagues who engaged in collecting and making sense of the field data. 
